\title{
FIRE PROTECTION FOR NON-STORAGE OCCUPANCIES WITH HIGH CEILING CLEARANCES
}

\author{
SOONIL NAM, ANTONIO BRAGA, HSIANG-CHENG KUNG, and JOAN M. A. \\ TROUP \\ FM Global Research, 1151 Boston-Providence Turnpike, Norwood, \\ Massachusetts 02062, U. S. A.
}

\begin{abstract}
Five large-scale fire tests were conducted to determine sprinkler protection requirements for non-storage occupancies with floor-to-ceiling clearance up to $18.3 \mathrm{~m}$. Examples of high-ceiling, non-storage occupancies are atrium spaces, movie theaters/studios, auditoriums, and some selected manufacturing facilities. The fire tests were conducted at a 18.3-m high test site using fuel arrays that were designed to simulate ordinary hazard fire scenarios. Sprinkler protection parameters and fuel arrangements were varied in the tests. The tests showed that:1) the sprinklers would provide adequate protection for these occupancies despite a clearance as high as $16.6 \mathrm{~m}$ from the top of the fuel stacks to the ceiling, 2) protection based on a 12- $\mathrm{mm} / \mathrm{min}$ discharge density over a $465-\mathrm{m}^{2}$ demand area was judged adequate for fire hazards equivalent to a FMRC Class 3 Commodity, 3) protection based on a $6-\mathrm{mm} / \mathrm{min}$ discharge density over a $232-\mathrm{m}^{2}$ demand area was adequate for fire hazards up to a Class 2 Commodity, 4) protection based on QR-ELO sprinklers delivering a $18-\mathrm{mm} / \mathrm{min}$ discharge density over a $232-\mathrm{m}^{2}$ demand area would provide adequate protection for high-ceiling occupancies exposed to a limited amount of plastic materials. Sprinkler skipping, extended sprinkler spacing, and protection of an occupancy with a ceiling higher than $18.3 \mathrm{~m}$ remain as subjects needing further study.
\end{abstract}

KEY WORDS: high ceiling clearance, non-storage occupancies, sprinkler protection

\section{INTRODUCTION}

Non-storage occupancies are defined here as occupancies containing potential fuel stacks that are lower than $3 \mathrm{~m}$. The ceiling clearance is defined as the distance between the top of the fuel stacks and ceiling. Examples of non-storage occupancies with high ceiling clearance are atrium spaces, movie sound stages/studios, exhibit halls, auditorium and sports areas, and various manufacturing facilities. There was a concern for whether or not the automatic sprinklers, which were installed on such a high ceiling, would actuate early enough to affect fire control. Some even doubted if the sprinklers would ever actuate.

Since there are no clear guidelines pertaining to protection for this type of occupancy, a few untested protection schemes have been widely applied without knowledge of their adequacy. Thus, research was needed to develop guidelines for automatic sprinkler protection for non-storage occupancies with high ceiling clearances.

Five full-scale fire tests were conducted at the 18.3-m high test site in the FM Global Test Center, West Glocester, Rhode Island, USA. The Test Center had a $61 \mathrm{~m}$ by $76 \mathrm{~m}$ test area under a continuous flat horizontal ceiling. All the doors and windows were closed 
during the tests and no forced ventilation was provided. The tests were designed to provide guidelines for protection of high ceiling clearance, non-storage occupancies that may contain fire hazards equivalent to those ranging from the Factory Mutual Research Corporation (FMRC) Class 2 Test Commodity through the FMRC Cartoned Unexpanded Group A Plastic Test Commodity. The fuel arrays were designed to simulate ordinary hazard fire scenarios. Sprinkler protection parameters that are commonly found at FM Global insured high-clearance, non-storage occupancies were used as the baseline conditions in the tests[1].

\section{FIRE TEST PARAMETERS}

\subsection{Test Fuels}

The FMRC Standard Class 2 Commodity served as the fuel in Tests 1 and 2. The commodity consists of a 1.07-m cube, double, triwall corrugated paper carton containing an open bottom sheet metal liner. The cartons have a combined nominal $25 \mathrm{~mm}$ thickness. Each fuel stack consisted of two double-up cartons (each $1.07 \mathrm{~m} \mathrm{x} 1.07 \mathrm{~m} \mathrm{x}$ $1.07 \mathrm{~m}$ high) supported on a wood pallet.

The FMRC Standard Plastic Test Commodity served as the fuel in Tests 3, 4 and 5. The Cartoned Unexpanded Group A Plastic Commodity consists of 125 empty polystyrene cups packaged in compartmented, single wall, corrugated paper cartons. Each fuel stack consisted of twelve cartons (each $0.53 \mathrm{~m} \times 0.53 \mathrm{~m} \times 0.53 \mathrm{~m} \mathrm{high}$ ) placed on a wood pallet. (See Fig. 1.)

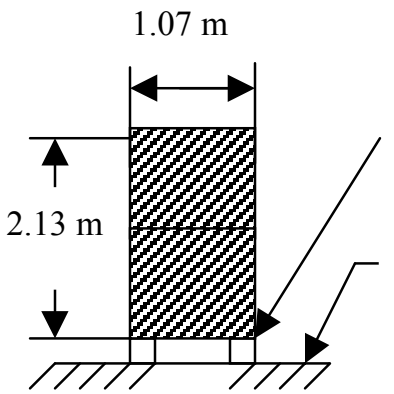

Tests 1 and 2
(Not to scale)

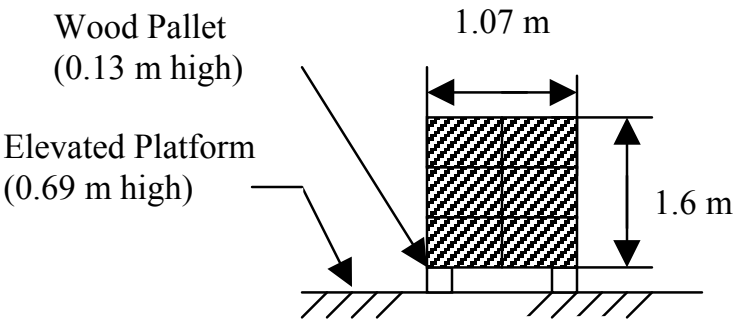

Tests 3, 4 and 5 (no platform in Tests 4 and 5)

Fig. 1 Side views of fuel arrays used in the tests.

\subsection{Fuel Array Arrangements}

The height of the fuel stacks in Tests 1 and 2 was $2.26 \mathrm{~m}$ and that in Tests 3, 4 and 5 was $1.73 \mathrm{~m}$. Since the fuel stacks were placed on a $0.69 \mathrm{~m}$ high platform in Tests 1 through 3 , the clearance from the top of the fuel arrays to the ceiling was $15.4 \mathrm{~m}$ in Tests 1 and 2 and $15.9 \mathrm{~m}$ in Test 3; Without the platforms, the clearance was $16.6 \mathrm{~m}$ in Tests 4 and 5 . The top view of the fuel array, 64 stacks of commodity arranged 8 by 8 , used in Tests 1 and 2 is given in Fig. 2. Stacks were separated by 0.15 m flues. Tests 3 and 4 used a different fuel array configuration. The top view of the three-row array is given in Fig. 3 . Sixteen stacks of the plastic commodity, arranged 2 by 8 , comprised the main fuel array. There were two target arrays, each single six-stack row, $1.5 \mathrm{~m}$ apart from the main fuel 
array. Adjacent stacks were separated by $0.15-\mathrm{m}$ flues. Test 5 used the same fuel array as in Tests 3 and 4, but different sprinkler locations; the top view is shown in Fig. 4.

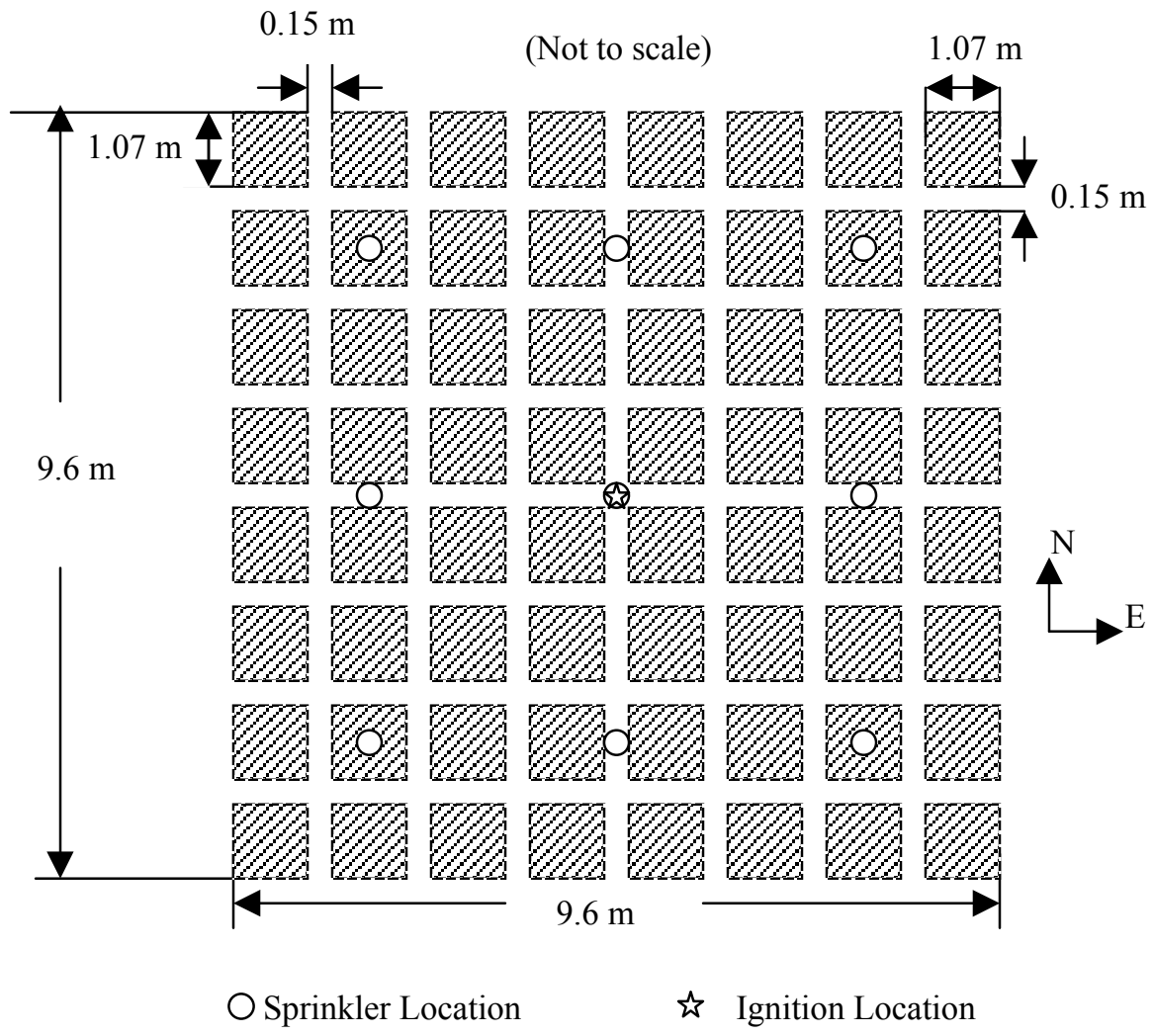

Fig. 2 Plan view of fuel array used in Tests 1 and 2.

\subsection{Sprinkler Protection}

Automatic sprinkler protection in all the tests was provided by upright sprinklers installed $165 \mathrm{~mm}$ below the ceiling. The temperature rating of the sprinklers used in Tests 1 through 3 was $74{ }^{\circ} \mathrm{C}$ and the Response Time Index (RTI) was $138(\mathrm{~m}-\mathrm{s})^{1 / 2}$. The temperature rating of the sprinklers used in Test 4 was $68{ }^{\circ} \mathrm{C}$ and RTI was $28(\mathrm{~m}-\mathrm{s})^{1 / 2}$. The temperature rating of the sprinklers used in Test 5 was $74{ }^{\circ} \mathrm{C}$, and RTI was $28(\mathrm{~m}$ s) ${ }^{1 / 2}$.

In Tests 1 and 3, nominal $13.5 \mathrm{~mm}$ orifice sprinklers supplying a $12-\mathrm{mm} / \mathrm{min}$ discharge density were used. In Test 2, nominal $12.7 \mathrm{~mm}$ orifice sprinklers supplied a $6-\mathrm{mm} / \mathrm{min}$ discharge density. In Test 4, nominal $16.3 \mathrm{~mm}$ orifice Quick Response, Extra Large Orifice (QR-ELO) sprinklers supplied a 18- $\mathrm{mm} / \mathrm{min}$ discharge density. In Test 5, nominal $25.4 \mathrm{~mm}$ orifice Quick Response, Extended-Coverage Control-Mode sprinklers supplied a 18- $\mathrm{mm} / \mathrm{min}$ discharge density. The sprinkler spacing in Tests 1 through 4 was $3 \mathrm{~m}$ by $3 \mathrm{~m}$, and that in Test 5 was $6.1 \mathrm{~m}$ by $6.1 \mathrm{~m}$. 


\subsection{Ignition Method}

Two FMRC standard full igniters, 76-mm dia. x 152-mm long cellucotton rolls, each soaked in $236 \mathrm{ml}$ of gasoline and enclosed in a plastic bag, served as the ignition source. The igniters were located in the center flue of each fuel array along the east-west direction. The ignition location was centered below a single ceiling sprinkler as shown in Figs. 2, 3 and 4. As the test program progressed, the sprinkler skipping turned out to be one of the most dominant parameters determining the efficacy of sprinkler protection. As the ignition directly under one sprinkler tends produce a more severe skipping than the other ignition locations do, it was rationalized that ignition directly under one sprinkler would provide a more conservative fire scenario than other ignition locations.

(Not to scale)

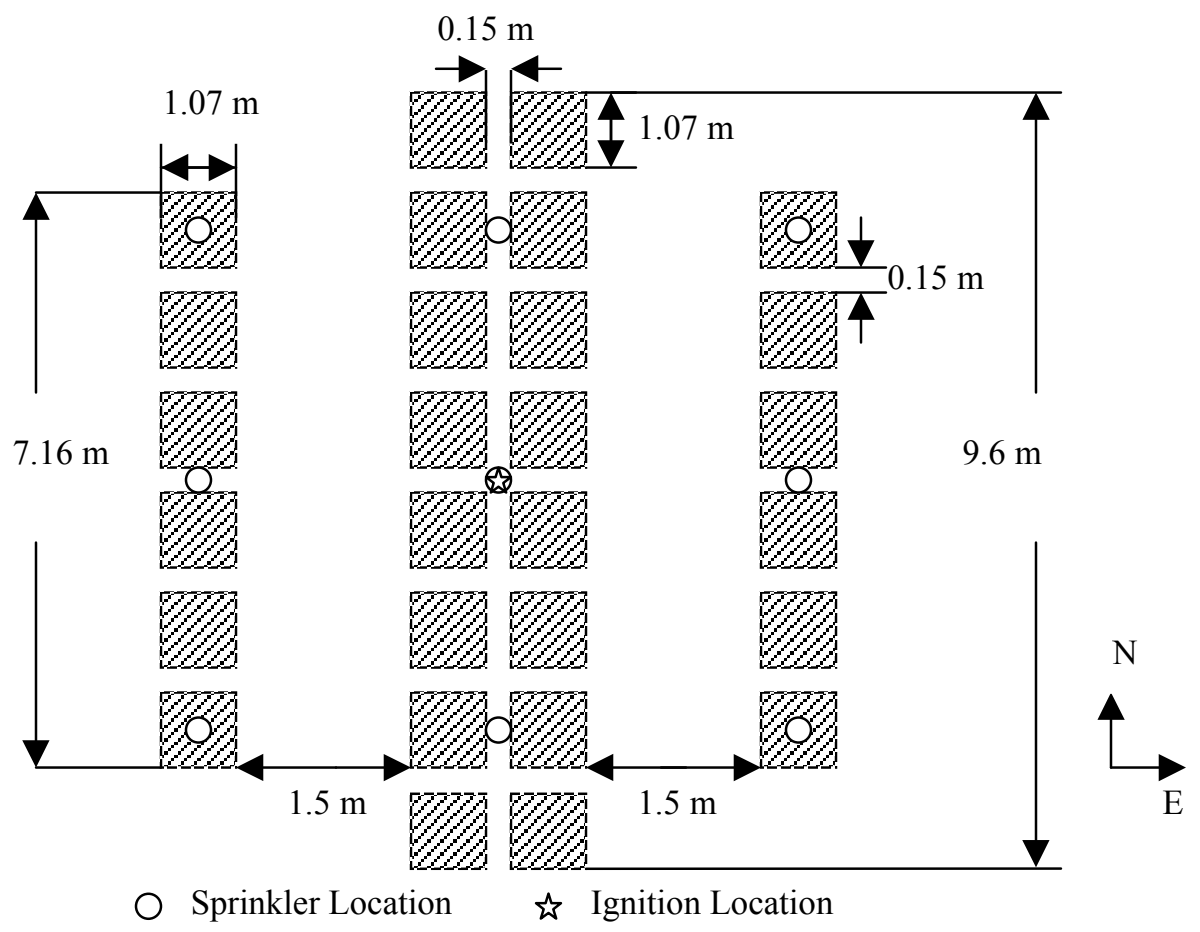

Fig 3 Plan view of fuel array used in Tests 3 and 4

\subsection{Instrumentation}

Sixty-four ceiling sprinklers in an 8 by 8 pattern were installed with timing mechanisms to monitor their opening sequence. Additionally in Tests 1 through 3, three fast response sprinkler links were attached to uncharged sprinklers. One fast response link, denoted as QR1, was adjacent to the center sprinkler. Another, denoted as QR2, was adjacent to the sprinkler located $3 \mathrm{~m}$ east of the center sprinkler and the other, denoted as QR3, was adjacent to the sprinkler located $6 \mathrm{~m}$ east of the center sprinkler. The response time index 
(RTI) of the fast response links was $28(\mathrm{~m}-\mathrm{s})^{1 / 2}$. They were installed to just show time responses without delivering any water.

○

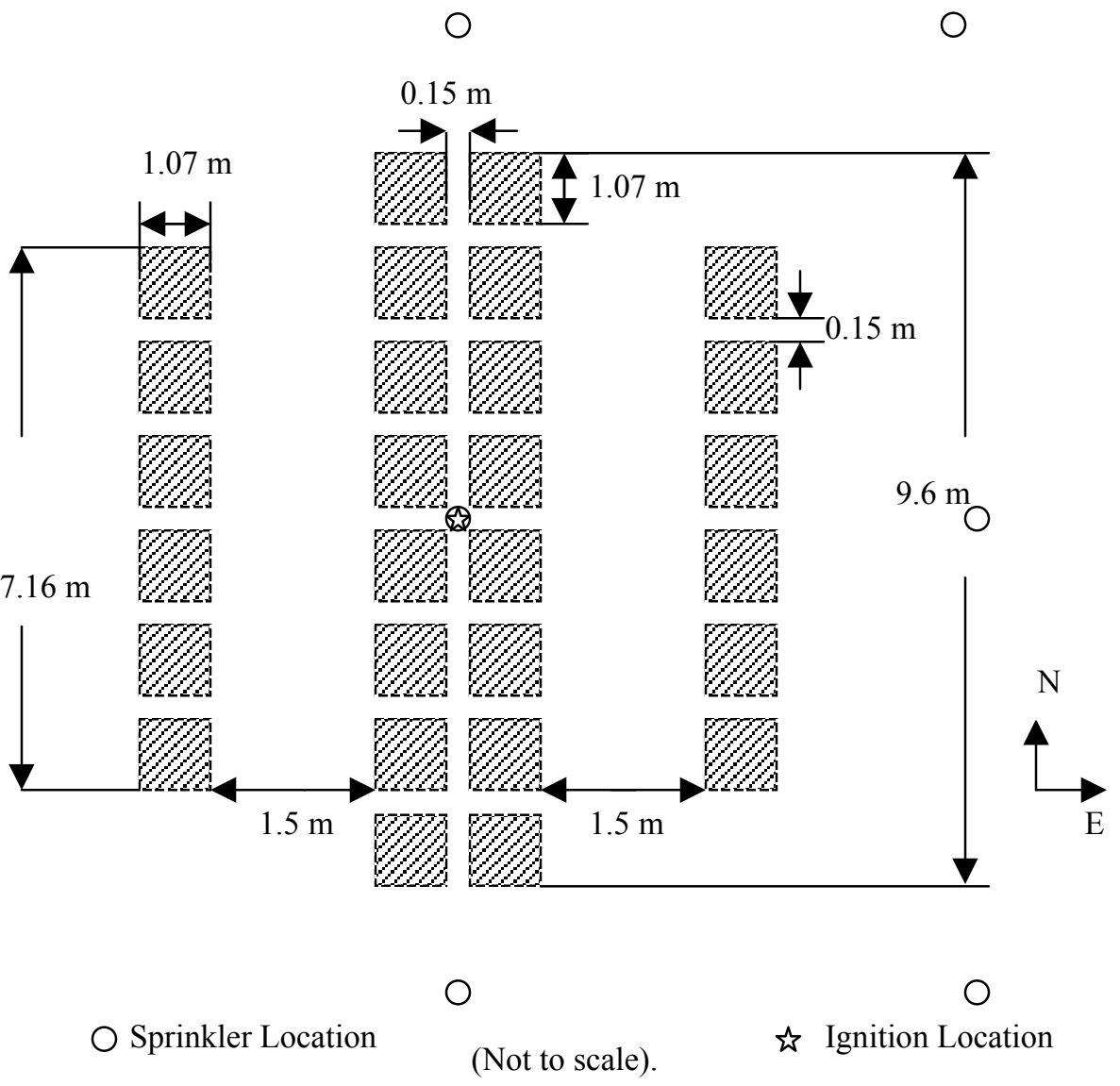

Fig. 4 Plan view of the fuel array used in Test 5.

Twenty-three thermocouples were installed $165 \mathrm{~mm}$ below the ceiling to measure near ceiling gas temperatures in Tests 1 and 2. They covered up to 26-m distances in the north, east, south and west directions from the ignition location. In Tests 3, 4 and 5, the measurement locations for ceiling gas temperature were increased to 42 .

Thermocouple trees were installed to measure gas temperatures at six elevations from the floor--- $3 \mathrm{~m}, 6 \mathrm{~m}, 9.1 \mathrm{~m}, 12.2 \mathrm{~m}, 15.2 \mathrm{~m}$, and $17.3 \mathrm{~m}$. Tree A was placed at the center of the main fuel array over the ignition location. The data from Tree A would indicate the flame intensity before and after the sprinkler actuation.

In Test 1, Trees B and C were placed, respectively, $1.2 \mathrm{~m}$ east and $1.2 \mathrm{~m}$ north of Tree A. In Tests 2 and 3, Trees B and C were placed $1.8 \mathrm{~m}$ east and $1.8 \mathrm{~m}$ north, respectively, of Tree A. In Tests 4 and 5, the locations of Trees B and $\mathrm{C}$ were moved to $3.2 \mathrm{~m}$ east and $3.2 \mathrm{~m}$ north, respectively, of Tree A. The temperature data recorded at Trees B and C 
would provide indications of whether or not fire spread into fuel stacks beyond the center four "ignition" stacks.

Five bi-directional differential flow probes were installed to measure the upward and the horizontal gas velocities generated by the fire plume. Two measuring locations were at Tree $\mathrm{A}$ at the 3-m and 9.1-m elevations above ignition. The other three locations were $0.15 \mathrm{~m}$ below the ceiling: one in the center flue aligned with Tree A; another $1.5 \mathrm{~m}$ south and $1.5 \mathrm{~m}$ east from the center; and the other $1.5 \mathrm{~m}$ south and $4.6 \mathrm{~m}$ east from the center. The mass loss history of the center four fuel stacks ( 2 by 2 ) was recorded by placing the stacks on a plate that was equipped with a load cell.

\section{TEST HIGHLIGHTS AND RESULTS}

\subsection{Test 1}

About 30 seconds after ignition, flames reached the tops of the fuel stacks. Flames reached at least $3 \mathrm{~m}$ above the top of the fuel array by $2 \mathrm{~min}$. The quick response sprinkler link over ignition, QR1, actuated at $2 \min 26 \mathrm{~s}$ and the first sprinkler actuated at 2 min 58 s. Quick response sprinkler link QR3, which was adjacent to the sprinkler located $6 \mathrm{~m}$ east from the first actuated sprinkler, responded at $4 \mathrm{~min} 51 \mathrm{~s}$. The response of quick response link QR2, which was closer to the ignition source than QR3, was not recorded during the test.

The second sprinkler actuated at $5 \mathrm{~min} 30 \mathrm{~s}$, a considerably long time after the first one. Thirteen more sprinklers operated during the next $1 \frac{1}{2}$ minutes; and, the last, the fifteenth sprinkler, actuated at $7 \mathrm{~min} 3 \mathrm{~s}$. The sprinkler opening sequence and the corresponding time of each actuation after ignition are given in Fig. 5. The dotted box represents the area covered by the fuel array. It should be noted that there was skipping of the entire second ring of sprinklers.

Even with 15 operating sprinklers, temperatures measured at Tree A, which are shown in Fig. 6, indicated that the fire maintained the same intensity for a while. The first sign of diminishing flames was evident at $9 \mathrm{~min}$. By then, the center four fuel stacks that were already engulfed in flames were being consumed, while pre-wetted fuel boxes hindered further fire spread. During the next few minutes, the fire continued to diminish and the test was terminated at $17 \mathrm{~min}$.

\subsection{Test 2}

QR1 actuated at $1 \mathrm{~min} 46 \mathrm{~s}$. The first sprinkler actuated at $2 \min 28 \mathrm{~s}$. QR3 actuated at 5 min. As in Test 1, the response of QR2 was not recorded. The second sprinkler actuated at 5 min $21 \mathrm{~s}$, almost 3 minutes after the first actuation. Then, fifteen more sprinklers actuated within two minutes. A total of 17 sprinklers operated; the last one actuated at 7 min $20 \mathrm{~s}$ (see Fig. 7). Even with 17 operating sprinklers, the temperatures measured at Tree A seemed to suggest that the fire remained at the same intensity for quite a while. The first sign of diminishing flames was evident by $13 \mathrm{~min}$. By then, the four center fuel stacks that were engulfed in flames were mostly consumed, while further flame spread was hampered because potential fuel was wetted. During the next $9 \mathrm{~min}$, the fire gradually diminished and the test was terminated at $22 \mathrm{~min}$. 


\subsection{Test 3}

For many existing occupancies that are exposed to a limited amount of plastic materials, the previously used close stacking of the fuel stacks was deemed too conservative an arrangement. The fuel arrangement was thus modified as shown in Figs. 3 and 4. A double row of Plastic Commodity, $1.73 \mathrm{~m}$ high stacks, was used as the main fuel array.

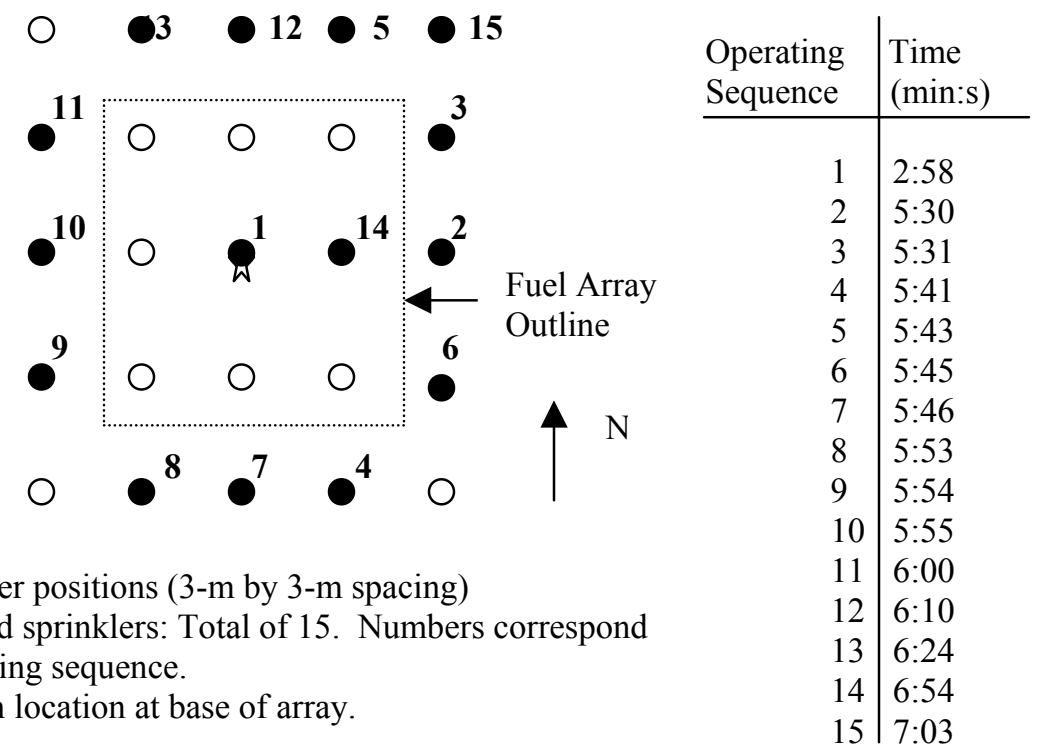

Fig. 5 Plan view of sprinkler operations in Test 1.

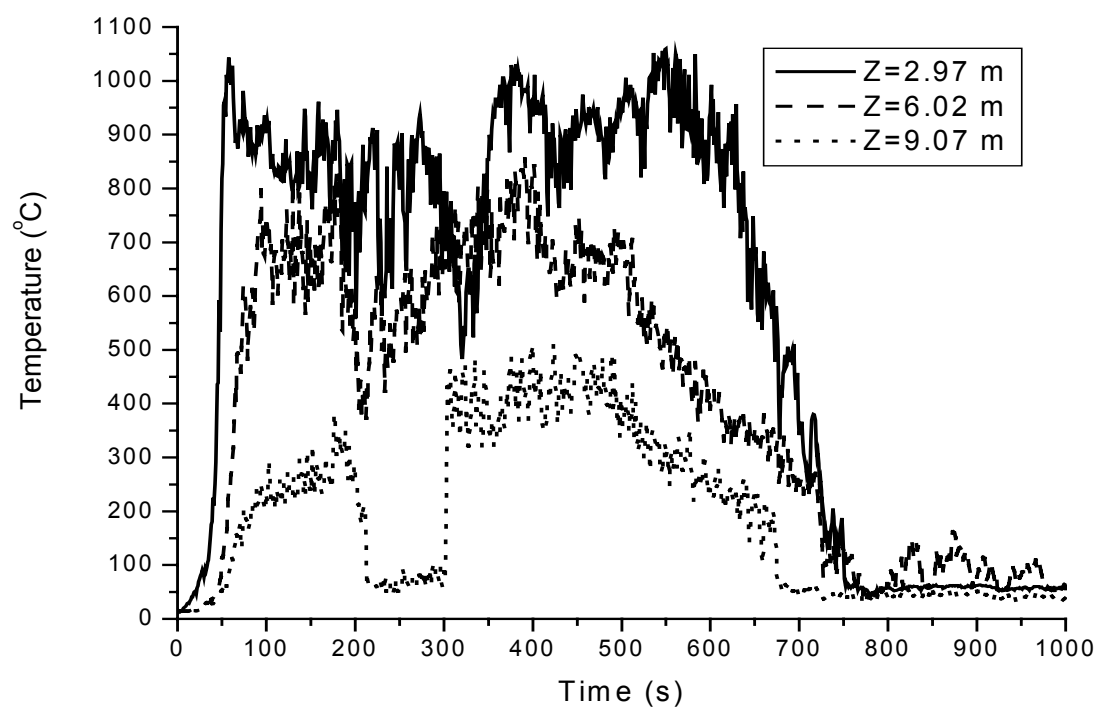

Fig. 6 Temperature measurements at Tree A in Test 1. 

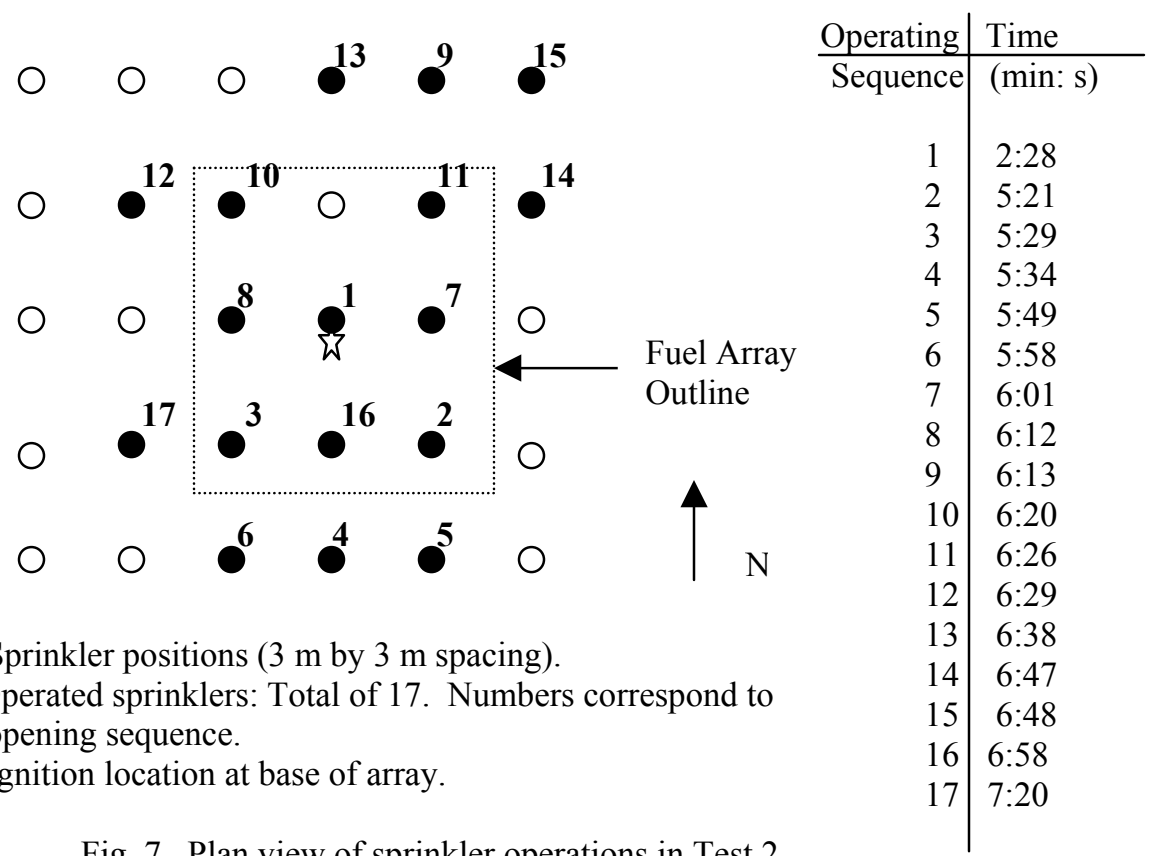

Fig. 7 Plan view of sprinkler operations in Test 2.

About 22 seconds after ignition, flames reached the tops of the fuel stacks. At 2 min $5 \mathrm{~s}$, the four center stacks were mostly engulfed in flame. Flames spread into stacks south and north of the center "ignition" stacks at $1 \mathrm{~min} 50 \mathrm{~s}$ and $2 \mathrm{~min} 55 \mathrm{~s}$, respectively. The fire spread, by radiative ignition, to the west target at $3 \mathrm{~min} 44 \mathrm{~s}$ and to the east target at 4 $\min 2 \mathrm{~s}$. The west target fuel array became more involved in the fire than the east target. QR1 responded at $1 \mathrm{~min} 46 \mathrm{~s}$ and QR2 responded at $1 \mathrm{~min} 59 \mathrm{~s}$. The first sprinkler actuated at $2 \min 21 \mathrm{~s}$. QR3 responded at $3 \mathrm{~min} 15 \mathrm{~s}$. After the first sprinkler operation, there was a considerable delay, $1 \mathrm{~min} 24 \mathrm{~s}$, before the second sprinkler actuated.

Thereafter, there were continuous openings of sprinklers for a total of 26 operating sprinklers by $7 \frac{1}{2}$ minutes as shown in Fig. 8 . The test was terminated at 9 min due to environmental regulations limiting the amount of smoke generation in a test. By then, the center four stacks in the main fuel array appeared almost completely consumed and the overall fire intensity appeared significantly diminished. However, it could not be verified conclusively with the data collected up to that point whether or not the fire would have been controlled. Other parts of fuel array, including the target arrays, were still involved in fire.

Sprinkler skipping played a very significant role. For the first time in the test series, sprinklers in the fourth ring actuated. The more open fuel arrangement in the test could have been one of the contributing factors. The fire spread farther out, compared with the previous fuel arrangement, within the same period of time. It is very likely that there would have been more open sprinklers, if the test had been allowed to continue. 


\subsection{Test 4}

The fuel arrangement was identical to that of the previous test; however, protection was changed to QR-ELO sprinklers supplying 18- $\mathrm{mm} / \mathrm{min}$ discharge density. The quick response links, QR1 through QR3, were no longer installed.

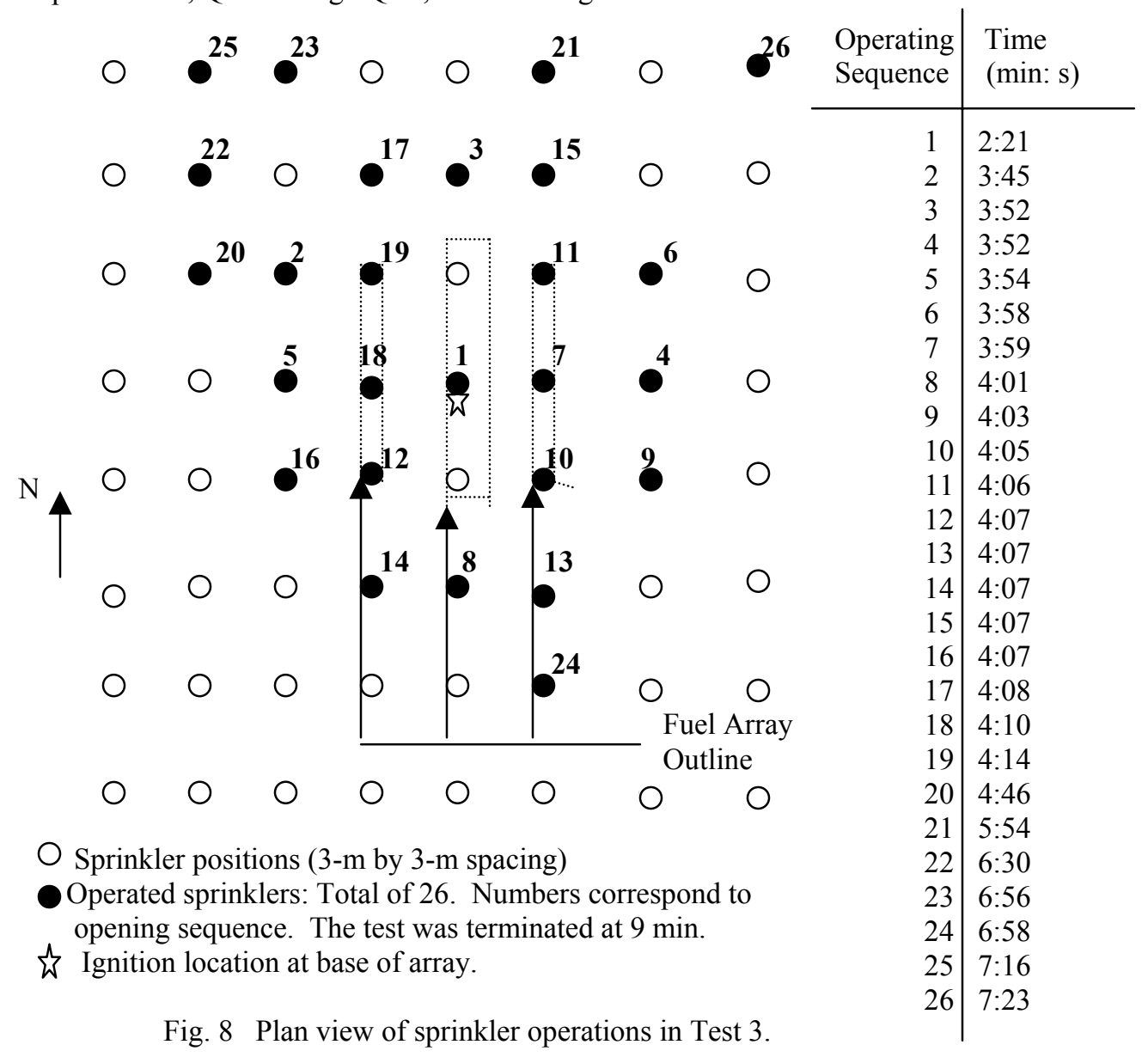

Flames reached the top of the fuel stacks, $1.73 \mathrm{~m}$ high, 28 seconds after ignition. The first sprinkler actuated was not the one directly above the ignition point, but was the one located $3 \mathrm{~m}$ south of the ignition point (see Fig. 9). As the fuel stacks located south of the four center stacks started to receive the water spray from the operating sprinkler, the fire seemed to spread in the other three directions. At 2 min $33 \mathrm{~s}$, the north fuel stack adjacent to the center four stacks was involved in fire. At $3 \min 41 \mathrm{~s}$ and $3 \mathrm{~min} 43 \mathrm{~s}$, two additional sprinklers actuated. The fire was still quite intense and showed no sign of diminishing. At $6 \mathrm{~min}$, many more sprinklers started to actuate. At $6 \mathrm{~min} 35 \mathrm{~s}$, the fire started to show signs of diminishing intensity. The last sprinkler, the $16^{\text {th }}$, actuated at 7 $\min 13 \mathrm{~s}$. The test was terminated at $15 \mathrm{~min}$.

As in all the previous tests, sprinkler skipping seemed to play an important role in the effectiveness of the sprinkler performance with respect to fire control. The degree of 
skipping was severe. None of the sprinklers immediately east of the center four fuel stacks actuated. The sprinklers immediately west of the center fuel stacks also skipped, but then actuated in a quite late stage of the test. Two of these sprinklers actuated last, even though they were located closer to ignition compared to some other sprinklers that actuated earlier.

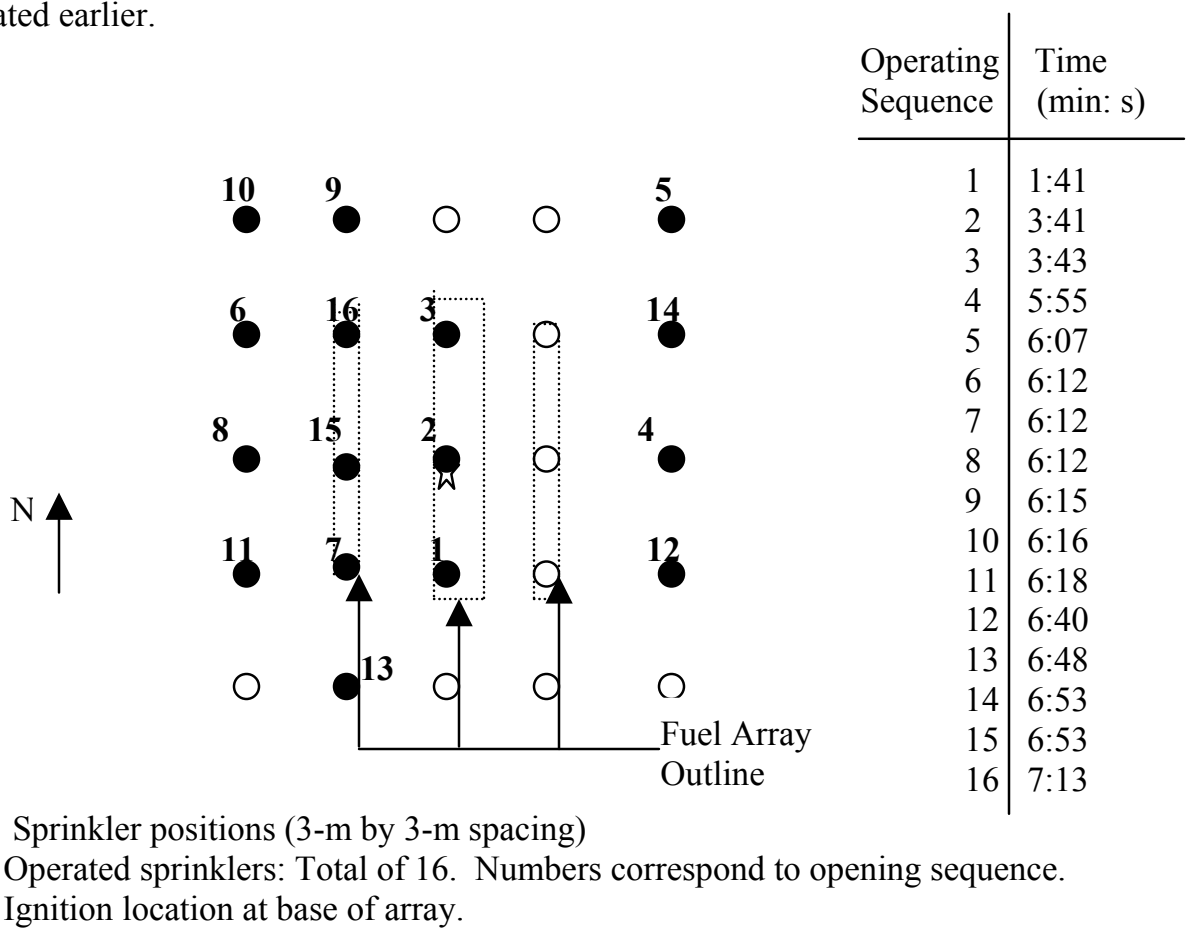

Fig. 9 Plan view of sprinkler operations in Test 4.

The test showed that the protection scheme used in the test would provide adequate protection against the fire hazard represented by the fuel arrangement. Fig. 10 shows the temperature measurements at Tree $\mathrm{A}$ in the test. If the sprinkler directly above the ignition point had actuated properly, the sprinkler opening pattern would have been different and the number of operating sprinklers could have been reduced. The ceiling gas temperature measurements showed that the ceiling gas temperature steadily decreased after the last sprinkler actuation at $\mathrm{t}=433 \mathrm{~s}$, which was another indication that the protection scheme used in the test was adequate.

\subsection{Test 5}

Test 5 was intended to explore using $6.1-\mathrm{m}$ by $6.1-\mathrm{m}$ spacing for the protection of nonstorage, high ceiling clearance occupancies. Since it became clear from the previous tests that $3-\mathrm{m}$ by $3-\mathrm{m}$ spacing would be subjected to sprinkler skipping, protection based on a larger sprinkler spacing had been proposed to possibly avoid sprinkler skipping. The sprinkler chosen for the test was the K-factor 25 Control-mode (Density/Area) ExtendedCoverage upright sprinkler, following the work of Heskestad[2]. Since a single test would be insufficient to evaluate the protection effectiveness of using the extended 
spacing, the test was intended to provide a reference point for future work. The test arrangement was identical to that of Test 4, except for the sprinklers and their locations (see Fig. 4).

At 2 min from ignition, the sprinkler over ignition actuated and discharged approximately $681 \mathrm{l} / \mathrm{min}$ onto the center four $(2 \times 2)$ "ignition" stacks. The fire started to lose intensity at $2 \mathrm{~min} 10 \mathrm{~s}$. At $4 \mathrm{~min}$, the view was completely obscured by smoke. It appeared that the fire had been confined to the four "ignition" stacks during the test. Test was terminated at $30 \mathrm{~min}$. Only one sprinkler operated.

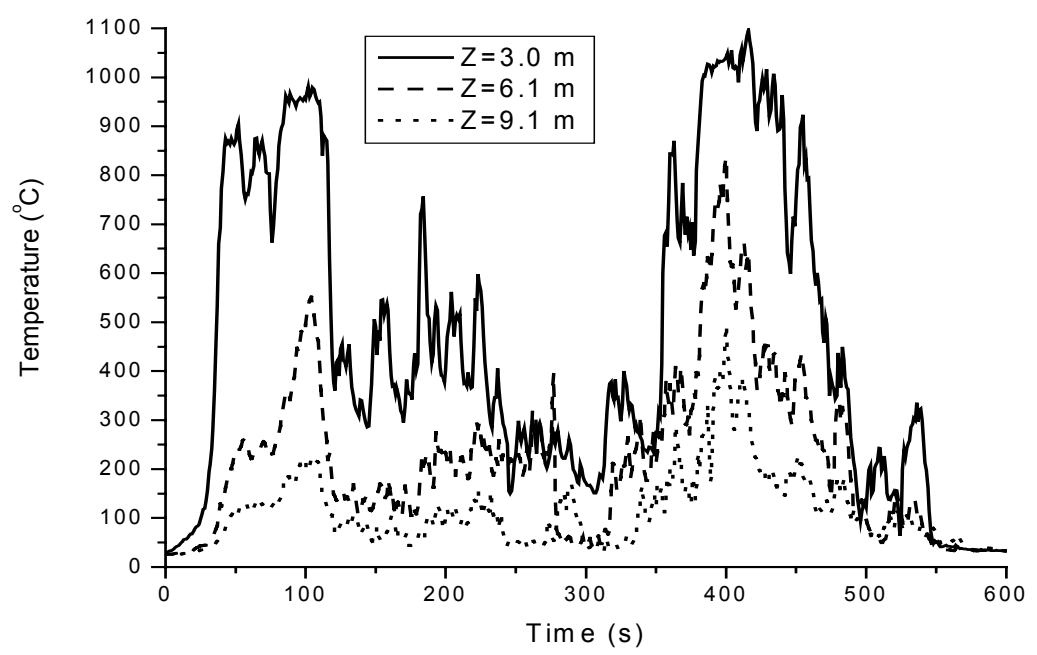

Fig. 10 Temperature measurements at Tree A in Test 4.

\section{SUMMARY AND CONCLUSIONS}

Five full-scale fire tests were conducted at the 18.3-m high ceiling site of the FM Global Test Center to determine adequate sprinkler protection for non-storage occupancies with high ceiling clearance. Test data such as the burning rate of the center fuel stacks, which was estimated through the load-cell data, flame/plume temperatures, ceiling gas temperatures, and sprinkler operating sequence were analyzed. Results of these tests showed that sprinklers installed at such a high ceiling clearance would indeed operate and that fire control would be achieved.

Tests 1 and 2 were conducted with $2.3-\mathrm{m}$ high stacks of the FMRC Class 2 test commodity. Sixty-four stacks were placed in an 8 by 8 pattern forming a solid pile fuel arrangement. In Test 1 , the adequacy of a $12-\mathrm{mm} / \mathrm{min}$ discharge density supplied over a 465- $\mathrm{m}^{2}$ demand area was assessed. Results were very favorable and all test evaluation criteria were met: only 15 sprinklers operated; ceiling level temperatures remained well within acceptable limits; and, the fire was well confined to the "ignition" fuel array. Because of the excellent results, it was concluded that the same level of protection can be extended to cover fire hazards equivalent to those involving a Class 3 commodity. 
In Test 2 , the adequacy of a $6-\mathrm{mm} / \mathrm{min}$ discharge density supplied over a $232-\mathrm{m}^{2}$ demand area was assessed. Results were nearly favorable: 17 sprinklers operated; ceiling level temperatures remained well within acceptable limits; and, the fire was confined to the "ignition" fuel array. Based on the results of the test, the provided protection was considered adequate for fire hazards up to the Class 2 commodity level. However, the number of the operated sprinklers was marginally within the number that can be regarded adequate for the given design area. A sufficient safety factor for the design area must be provided to prevent overtaxing of the water supply if too many sprinklers were to open.

Test 3 was conducted with slightly lower, 1.74-m high, stacks of a higher fire hazard commodity, the FMRC Cartoned Group A Unexpanded Plastic. Twenty-eight fuel stacks were spread out in three rows. Sixteen stacks, arranged in two by eight configuration, comprised the main fuel array. There were two single-row targets located across $1.5-\mathrm{m}$ aisle spaces on either side of the main array. The fuel arrangement was assumed to reflect the typical fire load that can be found at some manufacturing facilities or exhibit halls engaged in boat shows. For protection, nominal $13.5-\mathrm{mm}$ orifice sprinklers supplied a 12-mm/min discharge density. After 71/2 minutes from ignition, 26 sprinklers had operated. The test had to be terminated at 9 minutes before it yielded conclusive results.

Test 4 used the same fuel package as Test 3. For protection, an $18-\mathrm{mm} / \mathrm{min}$ discharge density was provided by nominal $16.3-\mathrm{mm}$ orifice Quick Response, Extra Large Orifice sprinklers. Results were favorable with all test evaluation criteria being satisfied. The results of the test showed that the provided sprinkler protection was effective against the fire hazard equivalent to the limited amount of FMRC Standard Plastic Commodity represented in the test.

Test 5 explored $6.1-\mathrm{m}$ by $6.1-\mathrm{m}$ sprinkler spacing. The fuel arrangement was identical to that of Test 3 or 4 . Protection was provided by nominal 25.4-mm orifice Quick Response, Extended-Coverage sprinklers supplying a $18-\mathrm{mm} / \mathrm{min}$ discharge density. The test results were favorable: only one sprinkler actuated; the fire was well confined within the four "ignition" stacks. However, additional tests are needed to verify the protection scheme before it can be recommended for specific installations.

Sprinkler skipping, which has not been a significant parameter in ordinary-clearance occupancies, played a very important role in the tests. Additional work is needed to study the effects on fire control due to both temporary and permanent sprinkler skipping in high ceiling clearance situations. Also, additional work is needed to determine protection recommendations for non-storage occupancies with even higher ceiling clearance.

\section{REFERENCES}

1. "Fire Protection Water Demand for Nonstorage Sprinklered Properties," FM Global Property Loss Prevention Data Sheet, 3-26, Factory Mutual Insurance Company, Johnston, Rhode Island, USA, 2001.

2. Heskestad, G., "Scaling of Water-Spray/Flame Interactions," Technical Report J. I. 0X1J4.RU, Factory Mutual Research Corporation, Norwood, Massachusetts, USA, 1999. 